\title{
Notas: uma cartografia; suspeitas e possibilidades acerca do corpo
}

\author{
Notas: una cartografía; sospechosas y posibilidades sobre el cuerpo \\ Notes: a cartography; suspicions and possibilities about the body
}

\author{
Marta Lizane Bottini dos Santos ${ }^{1}$ \\ Ursula Rosa da Silva ${ }^{2}$ \\ Ronaldo Luís Goulart Campello ${ }^{3}$
}

\begin{abstract}
Resumo
Este texto trata de se ocupar sobre uma pesquisa que versa de assuntos relativos ao corpo e o que demanda este tema. Alinha-se com questões pertinentes a práticas metodológicas docentes, e tencionam o arco de questões a partir de um viés cartográfico de pesquisa, e tal estudo se faz no Programa de Pós-graduação de Mestrado em Artes Visuais da Universidade Federal de Pelotas - UFPEL. O que se pretende ao tratar do corpo nesta pesquisa é antes de tudo, pensá-lo em sala de aula. Como é pensado? Se é pensado? Como professoras dos anos iniciais do ensino fundamental tratam tal assunto e se tratam como criam possibilidades de pensar/problematizar sobre as práticas cotidianas de ensinar e aprender sobre este corpo. O tema é extenso e palco para observações e discussões em muitas áreas do conhecimento: Filosofia, Artes, Ciências Biológicas, Educação, entre outras, e, possibilita criar linhas que escapam ao diálogo à medida que vamos adentrando ao tema e sendo atravessados por questões inquietantes que pedem a palavra ao tratar deste assunto, e para além das univocidades de que tratam tais ciências
\end{abstract}

Palavras-Chave: Corpo, corporeidade, cartografia, práticas docentes, arte-filosofia.

\section{Resumen}

Este texto trata de ocuparse de una investigación que versa de asuntos relativos al cuerpo y lo que demanda este tema. Se alinea con cuestiones pertinentes a prácticas metodológicas docentes, y tienen el arco de cuestiones a partir de un sesgo cartográfico de investigación, y tal estudio se hace en el Programa de Postgrado de Maestría en Artes Visuales de la Universidad Federal de Pelotas - UFPEL. Lo que se pretende al tratar del cuerpo en esta investigación es ante todo, pensar en el aula. ¿Cómo es pensado? Si se piensa? Como profesoras de los años iniciales de la enseñanza fundamental tratan tal asunto y se tratan como crean posibilidades de pensar I problematizar sobre las prácticas cotidianas de enseñar y aprender sobre este cuerpo. El tema es extenso y escenario para observaciones y discusiones en muchas áreas del conocimiento: Filosofía, Artes, Ciencias Biológicas, Educación, entre otras, y, posibilita crear líneas que escapan al diálogo a medida que vamos adentrando al tema y siendo atravesados por cuestiones inquietantes que piden la palabra al tratar de este asunto, y más allá de las univascidades de que trata estas ciências.

Palabras claves: Cuerpo, corporeidad, cartografia, prácticas docentes, arte-filosofía.

\begin{abstract}
This text tries to focus on a research that deals with subjects related to the body and what this theme demands. It aligns itself with questions pertinent to methodological teaching practices, and intends the arc of questions from a cartographic bias of research, and such study is done in the Master's Program in Visual Arts of the Federal University of Pelotas - UFPEL. What is intended to deal with the body in this research is, first and foremost, to think of it in the classroom. How is it thought? Is it thought? As teachers in the early years of elementary school
\end{abstract}

\footnotetext{
${ }^{1}$ Mestranda em Artes Visuais. Universidade Federal de Pelotas - UFPEL. Pelotas - RS marta.lizane@ gmail.com.

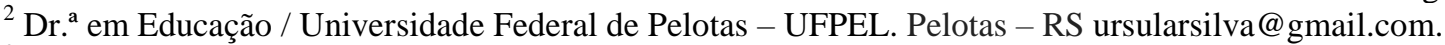

${ }^{3}$ Mestre em Educação e Tecnologia. Instituto Federal de Educação, Ciência e Tecnologia - IFSUL campus Pelotas - RS. ronaldo.campello@hotmail.com.
} 
they address this issue and are treated as they create possibilities of thinking / problematizing about the everyday practices of teaching and learning about this body. The theme is extensive and the stage for observations and discussions in many areas of knowledge: Philosophy, Arts, Biological Sciences, Education, among others, and allows to create lines that escape the dialogue as we go into the subject and being crossed by disturbing questions who ask for the floor when it comes to this subject, and beyond the univocalities that these sciences deal with

Key words: Body, corporeity, cartography, teaching practices, art-philosophy.

\section{Introdução}

Este texto trata de se ocupar sobre uma pesquisa que versa de assuntos relativos ao corpo e o que demanda este tema. Alinha-se com questões pertinentes a práticas metodológicas docentes, e tencionam o arco de questões a partir de um viés cartográfico de pesquisa, e tal estudo se faz no Programa de Pós-graduação de Mestrado em Artes Visuais da Universidade Federal de Pelotas - UFPEL; produzindo/propondo inquietações desde tempos em que esta aluna -agora pesquisadora- cursa sua Licenciatura em Artes Visuais nesta Universidade (2012), amenizando suas aflições quando encontra na literatura pós estruturalista suporte para responder algumas de suas agitações acerca do tema.

O tema é extenso e palco para observações e discussões em muitas áreas do conhecimento: Filosofia, Artes, Ciências Biológicas, Educação, entre outras, e, possibilita criar linhas que escapam ao diálogo à medida que vamos adentrando ao tema e sendo atravessados por questões inquietantes que pedem a palavra ao tratar deste assunto, e para além das univocidades de que tratam tais ciências, não quero aqui derrubar as frutas que já sem forças, mal conseguem suportar os ventos que tocam suas faces, mas sim, apanhar algumas destas frutas que podre estão e limpar um pouco, arejar/permitir que entre um sopro de ar fresco por entre seus galhos, que tortos nos levam a muitos lugares...

O que se pretende ao tratar do corpo nesta pesquisa é antes de tudo, pensá-lo em sala de aula, como se portam? Como é pensado? Se é pensado? Como professoras dos anos iniciais do ensino fundamental tratam tal assunto e se tratam como criam possibilidades de pensar sobre as práticas cotidianas de ensinar e aprender sobre este corpo. Portanto, algumas destas linhas que escapam levam ao conceito, por exemplo, de corporeidade que segundo Ahlert (2011, p. 04) “indica a essência ou a natureza do corpo. A etimologia do termo nos diz que corporeidade vem de corpo, que é relativo a tudo que preenche espaço e se movimenta". Cabe aqui tencionar o arco de questões e perguntar: este corpo que preenche espaço se movimenta em sala de aula?

O corpo é rico de possibilidades que podem ser explorados por professores de diferentes formas potencializando deste modo o aprendizado, mas, para trabalhar com este conceito, o educador deve compreender sobre questões relativas ao tema, pois, inúmeros 
autores problematizam o assunto a partir do arcabouço conceitual do qual faz seus estudos problematizando-o desta forma e criando assim, discussões que vem ao encontro de possibilidades ou não de melhor fruir sobre este assunto. Nos passos seguintes deste texto a proposta é caminhar ao lado de um ou outro autor, que aproxime suas ideias as desta pesquisadora, e ver sob suas perspectivas como observam este corpo... Em seguida, pretendese tratar como o método aqui apresentado, o cartográfico, e além das discussões tratar de expor, mesmo que minimamente, de onde surgiram as inquietações sobre este tema, e concluir este artigo não respondendo as perguntas aqui propostas, não tratar de por curativos e malagmas e pomadas sobre as feridas que se fizeram, mas sim deixá-las abertas e ir com o tempo vendo/observando estas feridas cicatrizarem e procurar ai, desta forma, um meio de aprender, e ir movendo-me em meio as discussões, as leituras, escritas e com o tempo buscar alcançar a fruta mais sadia que esta no topo da árvore, compreender como este corpo se faz em sala de aula, por exemplo...

Muitos autores quando falam sobre o corpo, tratam sobre o conceito de corporeidade; Ahlert (2011, p. 4), por exemplo, nos faz refletir sobre o termo nos trazendo em sua fala seu pensamento que "indica a essência ou a natureza do corpo. A etimologia do termo nos diz que corporeidade vem de corpo, que é relativo a tudo que preenche espaço e se movimenta, e que ao mesmo tempo, localiza o ser humano como um ser no mundo".

A corporeidade é o que esta para além de um conjunto orgânico, pele, músculos, fibras, tecidos ajustados sobre uma estrutura óssea que protege órgãos e que compõe em sua soma um sujeito que se relaciona com seus pares.

A compreensão do termo corporeidade vem unir o que a ciência durante séculos dicotomizou (corpo e mente). [...] é buscar entendê-lo [o ser humano] dentro da complexa teia de relações, que nos constitui e marca nossa existência no mundo; é valorizar igualmente todas as dimensões presentes na nossa história; é com elas encontrar-se, percebendo suas interações e relações na construção dos indivíduos e, principalmente, compreender que nossa existência se dá a partir de nossa corporeidade. (SOUSA, 2001, p. 195).

A corporeidade é analisada como sendo a ação do corpo a partir de atos experienciados. O corpo traz marcas sociais e históricas, cuja leitura norteia e delimita a ação do indivíduo em suas ações em coletividade (RODRIGUES, 2009).

Pois o individuo e [...] a espécie de animais que somos segundo o nosso modo de viver - vale dizer, nossa condição humana - ocorre no modo como nos relacionamos uns com os outros e com o mundo que configuramos enquanto vivemos (MATURANA, 2004, p. 9). 
Por corporeidade pode-se apreender a gestualização, a forma como nosso corpo fala, e o modo como ele o faz. Um olhar perdido, um franzir de testa, sobrancelhas. Um estar inquieto no assento, um não parar de movimentar pés ou mãos, enfim. São inúmeras as formas como nosso corpo se expressa. E pensando nas crianças e nos jovens estudantes, que se encontram nos bancos escolares, e no tanto de disposição que existe nesta fase da vida de seus corpos ainda joviais, sendo docilizados.

É inicialmente na escola que desenvolvemos as primeiras noções de relações sociais, convivendo desde bem cedo (pré-escola) com nossos pares, e, neste processo que segue até a vida adulta necessitamos de direcionamentos que nos capacitam ao convívio em sociedade. De tal modo, é imperativo compreender que se o docente tiver um olhar mais compassivo e distinto para o mundo pode direcionar o educando a uma participação mais plena/total em suas aulas, de forma criativa e instigadora.

Acredita-se que o professor seja aquele que possa ser/fazer a diferença dentro da sala de aula, como também em sua escola, contribuindo na edificação do conhecimento possibilitando e fomentado assim, a construção de um público ávido em suas mais distintas formas de expressão e desta forma se pensa que tratando com mais acuidade temas pertinentes ao corpo, possibilitando que os educandos tenham outras formas de aprender sobre seu currículo disciplinar.

Aprende-se brincando, e a criança em seu imaginário se desenvolve mais plenamente desta forma. Proporcionar abordagens mais ricas em atividades nas quais estes educandos descubram seu corpo através, por exemplo, do Teatro, da Dança, das Artes Cênicas são alternativas de educar de uma forma mais abrangente...

\section{Corpo como aparelho de mudanças}

Nos tempos atuais temos o corpo no seio central de inúmeras discussões. O corpo é moeda usual, instrumento onde mudanças e conquistas ocorrem, por exemplo, nas áreas médica e estética, neste novo século, ainda com mais abrangência. A tecnociência, e os inúmeros avanços nas práticas de medicina em virtude de uma grande expansão na área das tecnologias provocam/proporcionam estes avanços. A beleza eterna que se busca, e se constitui em práticas de exercícios físicos a todo instante propagados como aliados de um bem estar emocional/social transformando a forma física do corpo que se molda a cada época em sinônimo de saúde e beleza. Nesta atual época, exigem-se corpos magérrimos e bem delineados. Envelhecer não é mais permitido, "a morte e a velhice que surgem para atemorizar este homem que hoje é biotecnológico prende-se ao "culto ao corpo" (SIBILIA 
2012, p. 151). As sociedades atuais cultuam em demasia o corpo que em sua estrutura literal, busca ainda cumprir seu papel e funções. Porém, na atual sociedade este corpo bem delineado é sinônimo/status de consumo, objetivo a ser alcançado. Neste caso é a síntese do embate entre o envelhecimento/morte, trazendo uma concepção de corpo redefinido, o velho torna-se um estigma porque está à mercê do tempo e da natureza. A negação do próprio corpo insta a conquistar a qualquer custo à visibilidade e a celebridade midiática para poder 'ser alguém' na sociedade atual (SIBILIA, 2012, p. 149). O corpo se torna um instrumento para fixar sujeitos no seio social, do qual se quer fazer parte. Ocorre o hibridismo entre a carne e técnica que enfatiza a fabricação de biomateriais, que são mesclados aos terminais nervosos e musculares, ao associar ciências biológicas, informática e robótica. Se desenha um novo mundo de sentidos, com a definição esperançosa que precisa ir além dos seus limites tradicionais e de configurações impostas. Porém, é recorrente a visão que considera o corpo como

obsoleto, despojado de valor, tornado insípido e suscetível de todos os emparelhamentos tecnológicos ou de todas as experiências extremas para ampliar suas possibilidades, suprimi-lo ou converte-lo em simples suporte (LE BRETON apud STERLAC, 2013, p. 52).

O corpo ampliado pela biotecnologia vai deixando de lado um corpo obsoleto que se transforma com o passar dos anos. E no cerne de tantos avanços que vem ocorrendo se torna relevante "refletir sobre as desordens e diferenciados ordenamentos decorrentes dos avanços tecnológicos".

Guacira Lopes Louro nos diz que "o corpo é o que se diz dele" (p. 12) ao passo dos longos dilemas contemporâneos que estabelecem um percurso entre a construção individual do corpo e sua gestão social sendo que estes dilemas perpassam por questões como "bioética, bioestética, biopoder e biotecnologia” (COUTO; GOELLNER, 2012, p. 8) estimulados por/diante de, um mundo em transformação onde se vive uma "progressiva banalização da experiência humana. Essa condição nos traz imensos desafios, como a urgência de construir corpos nos ritmos acelerados das mudanças tecnológicas" (COUTO; GOELLNER, 2012, p. 8). O corpo que hoje possibilita discussões, busca de forma incessante, a beleza eterna, que se constitui nos mais íntimos/fugazes desejos. E desejar é construir agenciamentos, pois "nunca desejamos algo só, sempre em um conjunto de coisas ${ }^{4}$.

\footnotetext{
${ }^{4}$ Ideias elaboradas a partir da letra "D" de Desejo, contidas no Abecedário. O Abecedário de Gilles Deleuze é uma realização de Pierre-André Boutang, produzido pelas Éditions Montparnasse, Paris. No Brasil, foi divulgado pela TV Escola, Ministério da Educação. Tradução e Legendas: Raccord [com modificações]. Disponível em: https://www.youtube.com/watch?v=uojVXjdBwg0 > acessado em 02/09/15.
} 
O ser humano vem experimentando, nos últimos anos, um processo de transformação, no seu modo de vida. Para Sibilia (2012, p. 145) "os corpos humanos podem cada vez mais, e podem durante mais tempo". É desde os anos 50 que a experiência de mixar corpo e as tecnologias vem deslocando da ficção para o cotidiano das pessoas, do marca-passo aos chips; dos condutores elétricos que emitem sinais nervosos do cérebro para os órgãos; as diversas próteses instaladas no corpo para superar deficiências, curar doenças, realçar aspectos da beleza, favorecer a juventude e revitalizar o desempenho corporal; "os confins do corpo humano estão sendo redefinidos" (SIBILIA 2012, p. 146).

Á tecnociência, possibilita ser quem quiser e a incisão de inúmeras práticas cirúrgicas possibilita, inclusive, a troca de sexo. Nasce-se homem e ocorre à mudança para assumir-se como mulher e vice-versa, "o principio de identidade torna-se tão obsoleto quanto às formas corporais indefinidamente remanejáveis" (LE BRETON, 2013, p. 49). O corpo parece feito de "máquina, imagens e informações" (SANTAELLA apud DYENS, 2007, p. 130). Os corpos aparecem "borrados, moldados e transformados pela tecnologia" (ib).

\subsection{Sobre a beleza e o corpo}

A Filosofia proporciona reflexões acerca de questões pertinentes ao convívio social. Francisco Romão Ferreira em "Ciência, Arte e Cultura no Corpo: A construção de sentidos sobre o corpo a partir das cirurgias plásticas" traz um diagnóstico amplo de como o corpo foi observado, desenhado, diagnosticado sob as "três asas do conhecimento: Arte, Filosofia e Ciência" nos últimos séculos (FERREIRA 2011, p. 77). O autor citado faz observações precisas de como as "principais correntes artísticas, por exemplo, no século XIX iriam pintar o corpo" (ib.) e, de como se iriam representá-lo. Muitos artistas trazem dentro dos movimentos artísticos como, por exemplo, o Romantismo, Naturalismo, Realismo, Impressionismo, esta representação do corpo adequando-o a cada época, mas, é o Modernismo que vai reunir "correntes artísticas que se propõem a interpretar, apoiar e acompanhar o esforço progressista, econômico e tecnológico, da civilização industrial" (FERREIRA 2011, p. 78). Sendo que, nos dias de hoje "a beleza passa a ser realidade, a massificação e a homogeneização como partes constitutivas do mundo moderno industrial em ascensão" (FERREIRA 2011, p. 79).

No inicio do séc. XX se vê "uma mudança radical da silhueta e dos padrões de beleza corporal, principalmente para as mulheres" que são as que 'mais sofrem' (FERREIRA et al, 2011, p. 80) com as imposições dos novos padrões de beleza imposta. Mesmo que cada corpo possua suas características, atualmente se está imerso em uma sociedade que cultua o corpo, 
valoriza-o em demasia. E ocorre que o sujeito se adéqua aos padrões de beleza vigente das sociedades nas quais esta imerso, o corpo sofre com as conformações das sociedades nas quais esta instalada. São os corpos malhados e delineados, com curvas corretas cujo sinônimo é de beleza e saúde. Parece que o sujeito contemporâneo esta vinculado ao status que os discursos sobre a estética do corpo impõem. E, é "especialmente com a estética, um dos marcadores por excelência do status de saúde do corpo na atualidade” (GUTTERRES, 2015, p.15).

O filósofo contemporâneo Michel Foucault mostra, em suas pesquisas, como o corpo, na modernidade, a partir de uma sociedade disciplinar, conseguiu, através de técnicas próprias, docilizar e moldar sujeitos, em prol de interesses da sociedade onde "a racionalização da sociedade ocidental que encontrou no corpo humano um novo objeto de exploração e controlo. A modernidade terá sido por isso, responsável pelo desenvolvimento de uma nova forma de poder centrada no corpo" (PEREIRA apud FOUCAULT, 2010, p. 45) e pensando sobre isso, refletindo sobre práticas pedagógicas possíveis penso se este corpo é pensado em sala de aula, é discutido frente a todos estes temas, por exemplo, aqui ressaltados.

\subsection{Cartografando práticas e docências}

A proposta deste trabalho utiliza o método cartográfico de pesquisa proposto por Deleuze e Guattari (1995) o qual possibilita trabalhar de um modo onde o que nos interessa mais são os processos, e não o que resulta das investigações, ou seja, as oscilações da/na construção das atividades, as discussões, o que se propôs a fazer, e como foi feito. "Cartografar é acompanhar um processo, e não representar um objeto" (KASTRUP, 2008, p. 469). "A proposta cartográfica de investigação não prestigia os fins em si, mas os meios, os fazeres e não a conclusão" (CAMPELLO, 2016, p. 21), faço cartografia quando me proponho a ler, escrever; reescrever e sempre inquietar-me com o que esta sendo produzindo, ou com o que esta sendo e como esta sendo problematizado. Sempre pensar maneiras novas, ou não, de questionar o que se propõem a cartografar.

A experiência como aluna no curso de Artes Visuais, e posteriormente, nas observações realizadas no período de estágio (2012/15), potencializou refletir sobre a ação docente e dos assuntos acolhidos sobre o corpo para atuar dentro da sala de aula, ou seja, este tema, o corpo, me inquieta desde algum tempo, desde quando observo os conteúdos programáticos que são dispostos aos professores e não se tem temas que possam ser pertinentes à discussão sobre o assunto tratando com mais profundidade, adentrando em águas mais turvas e mais profundas, assim como, também mais revoltosas. A escola não relativiza 
muita acuidade a temas relativos ao corpo, quando faz traz a tona à sexualidade e a cuidados nos modos de se relacionar, a como utilizar este corpo para a prática de exercícios físicos, não menos importante, mas não creio que seja só isso, é preciso mais, é um modo, uma investida superficial.

O professor assume o papel de contribuir na edificação do conhecimento da criança, cujo objetivo é buscar a construção de um público ávido em suas mais distintas formas de expressão. O corpo pode ser um rico manancial no processo de ensino/aprendizagem, possibilitando um novo diálogo sobre os diversos contextos do sujeito.

No modo de ensinar contemporâneo o professor tem a possibilidade de utilizar-se dos recursos que achar necessário para potencializar seus alunos para o despertar de práticas que possibilitem reflexões, intervenções de forma inventiva e instigadora e discorrer sobre o corpo como instrumentos que ofereçam aos docentes e discentes possibilidades de explorar, de distintos modos, o aprendizado em detrimento a uma atitude e de métodos que possibilitem criar ambientes solícitos ao ensino potencializando a criatividade e lúdico do educando possibilitando um derrame que extravase de forma consciente e inventiva seu modo de se expressar. Ao trabalhar com tais conceitos, exige do educador um envolver-se, um questionar ações acerca do corpo e da corporeidade, um pensar sobre o assunto em contextos que manifestam-se incidentes, não só em sala de aula, mas em um contexto mais amplo, pensar sobre as questões que envolvem o corpo na sociedade desta época.

Realizo cartografia quando regresso nas leituras e escritas deste texto e o refaço, uma, duas, três ou mais vezes, desta forma não sou mais a mesma de antes, porque sempre acrescento coisas novas, retiro o que já esta gasto, observo com outros olhos estas linhas e repenso sobre este corpo que tanto me inquieta, vejo outras possibilidades de pensar práticas docentes que interajam com este corpo dócil que esta sendo sentado nas classes de sala de aula gritando, pulando, sacudindo-se, pedindo para ir ao banheiro uma, duas, três ou mais vezes. Ando por caminhos que não são mais os mesmos. "O cartógrafo é formado nas problematizações do mundo, nos desvios, nos lapsos, ali onde algo escapa ou onde não encontramos o que ansiamos encontrar" (POZZANA, 2014, p. 61).

\section{Encerrando (por agora...)}

Ao tempo que cada sociedade que se forma, de tempos em tempos, percebemos os novos contrastes que se fundam e as marcas que se tornam visíveis nos costumes, nas vestimentas, e temos/percebemos nos corpos mais evidentemente tais mudanças. $\mathrm{O}$ trabalho de pesquisa ao qual se refere este texto encontra-se em andamento, no entanto, esta escrita 
trouxe algumas reflexões acerca de assuntos referentes ao corpo, e como este tema gera discussões, a partir da compreensão que temos na ciência a qual estamos imbricados, por exemplo, às práticas pedagógicas docentes, práticas de sala de aula nas series iniciais, observadas desde um remoto período, enquanto graduanda no curso de Licenciatura em Artes Visuais que provocam inquietações que ainda seguem pulsantes e fortes no que trata sobre estes temas, tendo a cartografia como proposta de método de pesquisa buscando compreender este corpo como é pensado, se é, no contexto de sala de aula.

Ao refletir justificativas sobre o estudo deste tema neste trabalho e sobre a opção de argumentos indicativos ao corpo pretende-se com isso potencializar reflexões sobre ajuizamentos sociais, que desde a infância forjam sujeitos. Neste trabalho buscou-se trazer reflexões sobre o corpo em sala de aula, trazendo a discussão observações de autores que problematizam este tema, e contextualizam sobre a beleza do corpo, e este corpo pósorgânico, e alio a estas falas inquietações observadas em sala de aula enquanto este corpo é manancial de possibilidades aos professores e alunos a ser explorado de diferentes formas, em prol ao processo de aprendizagem de técnicas, expressões e a fruição, potencializando o lado 'criador' e lúdico da criança para que transborde e extravase de forma consciente e criativa.

Potencializar reflexões sobre assuntos relacionados ao corpo e a corporeidade, são necessários. A educação sobre o corpo, atualmente, assume um papel significativo como recurso nas práticas pedagógicas, pois o corpo é fluido, líquido, alterando-se e formando-se, a partir de novos conceitos cotidianos.

Pensar o corpo, atualmente, assume um papel significativo como recurso nas práticas pedagógicas; sendo que o corpo é fluido, líquido, alterando-se e formando-se, a partir de novos conceitos cotidianos, para tanto é preciso que exista sensibilidade e referencial teórico adequado para tratar com o referido tema.

\section{Referências}

AHLERT, A. Corporeidade e educação: o corpo e os novos paradigmas da complexidade. Revista Ibero-americana de Educação. ISSN: 1681- 5653 - $\mathrm{n}^{\circ} .56 / 1-15 / 07 / 2011$. In: Disponível em <http://www.rieoei.org/deloslectores/3880Ahlert.pdf> acesso em 16/06/2012.

CAMPELLO, R. L. G. Cartas para ler e escrever. Cartografando uma prática de ensino. 2016. 78f. Dissertação (mestrado) - Instituto federal de Educação, Ciência e Tecnologia Sulrio-grandense, Programa de Pós Graduação em Educação, Mestrado Profissional em Educação e Tecnologia, Pelotas, 2016. 
COUTO, E. S. As façanhas dos extremos. O triunfo do corpo nas atividades físicas e esportivas radicais. In O triunfo do corpo: polêmicas contemporâneas/ Edvaldo Souza Couto, Silvana Vilodre Goellner, (Orgs.). - Petrópolis, RJ: Vozes, 2012. Vários Autores.

DELEUZE, G. GUATTARI, F. Mil Platôs: Capitalismo e Esquizofrenia, v.1. Rio de Janeiro: Editora 34, 1995.

FERREIRA, F. R. Ciência, arte e cultura no corpo: A construção de sentidos sobre o corpo a partir das cirurgias plásticas. Editora CRV. Curitiba - Brasil. 2011.

FOUCAULT, M. Historia da sexualidade I. A vontade do saber. Tradução de Maria Thereza da Costa Albuquerque e J. A. Guilhon Albuquerque. Rio de Janeiro, Edições Graal, 1988. in. Do original em francês: Histoire de la sexualité I. la volonté de savior.

GUTTERRES, B. R. Lições sobre corpos e estilos de vida nos anúncios publicitários de academias de ginástica. 2012. Dissertação de Mestrado apresentada ao Programa de PósGraduação em Educação da Universidade Luterana do Brasil - ULBRA - como parte dos requisitos para a obtenção do título de Mestre em Educação. Disponível em: < https://servicos.ulbra.br/BIBLIO/PPGEDUM150.pdf > acessado em 15/09/15.

KASTRUP, V. O método da cartografia e os quatro níveis da pesquisa-intervenção In: CASTRO, L. R. de; BESSET, V. L. (Orgs.). Pesquisa-intervenção na infância e juventude. Rio de Janeiro: Trarepa/FAPERJ, 2008, p.465-489. Disponível em: <http://pepsic.bvsalud.org/pdf/epp/v10n1/v10n1a07.pdf> acessado em 30/08/2015.

LE BRETON, D. Adeus ao corpo: Antropologia e sociedade/ David Le Breton; tradução Marina Appenzeller. - $6^{\text {a }}$ ed. - Campinas, SP: Papirus, 2013.

LOURO, G. L. Desafios. in O triunfo do corpo: polêmicas contemporâneas/ Edvaldo Souza Couto, Silvana Vilodre Goellner, (Orgs.). - Petrópolis, RJ: Vozes, 2012. Vários Autores.

MATURANA, H. R. - Amar e brincar: fundamentos esquecidos do humano do patriarcado à democracia / Humberto R. Maturana, Gerda Venden. Zöller; tradução de Humberto Mariotti e Lia Diskin. - São Paulo: Ed. Palas Athenas 2004.

PEREIRA, A. L. Do "cuidado de si” nas ginásticas de academia. In: GOMES, Rui Machado et al. (Orgs.). O corpo e a política da vida. Lisboa: Editora Rui Machado Gomes, 2010.

POZZANA, L. A formação do cartógrafo é o mundo: Corporificação e afetabilidade. In Pistas do método da cartografia: a experiência da pesquisa e o plano comum/organizado por Eduardo Passos, Virginia Kastrup e Silvia Tedesco - Porto Alegre: Sulina, 2014. 310 p. (2).

SANTAELLA, L. Pós-humano Por quê? Revista USP, São Paulo, n.74, p. 126-137, junho/agosto 2007. Disponível em: < http://www.usp.br/revistausp/74/09-luciasantaella.pdf> acessado em 02/09/15.

SIBILIA, P. Imagens de corpos velhos. A moral da pele lisa nos meios gráficos e audiovisuais. In O triunfo do corpo: polêmicas contemporâneas/ Edvaldo Souza Couto, Silvana Vilodre Goellner, (Orgs.). - Petrópolis, RJ: Vozes, 2012. Vários Autores. 
SOUSA, H. H. L. de. Vygotsky e o brinquedo: corporeidade e aprendizagem. Comunicações. Piracicaba. v. 8, n. 1, p. 192-196, jun. 2001. 